\title{
Meeting UK heat demands in zero emission renewable energy systems using storage and interconnectors
}

\section{Tiziano Gallo Cassarino ( $\nabla$ t.cassarino@ucl.ac.uk)}

University College London https://orcid.org/0000-0001-9220-2360

\section{Mark Barrett}

University College London

\section{Research Article}

Keywords: Energy systems, heat decarbonisation, costs, storage, renewables, interconnectors

Posted Date: June 16th, 2021

DOI: https://doi.org/10.21203/rs.3.rs-629226/v1

License: (c) (i) This work is licensed under a Creative Commons Attribution 4.0 International License. Read Full License

Version of Record: A version of this preprint was published at Applied Energy on January 1st, 2022. See the published version at https://doi.org/10.1016/j.apenergy.2021.118051. 


\section{Abstract}

With over a third of the United Kingdom's greenhouse gas emissions, decarbonising heat is key to achieving the Government's net-zero target by 2050 . Here, we simulate high renewable zero-emission energy system architectures with heat supply based on the major options of district heating, heat pumps, and electrolytic hydrogen boilers. We adopt a novel whole system modelling approach that combines meteorology-driven hourly simulations of demand and supply with storage, flexible technologies, and interconnections on the European scale. Our results show that systems with heat supply based on consumer or district heat pumps require about four times less electricity per unit of heat, with a heat cost about half of that from electrolytic hydrogen boilers. Furthermore, we compare trade-offs between investment in different infrastructure components. For example, we find that, compared to the reference scenario, increasing renewable capacity by $33 \%$, or interconnections by $200 \%$, can lower system storage capacity by up to $50 \%$.

\section{Introduction}

Heating accounted for about $37 \%$ of the UK's carbon emissions in 2017[1] but this is now approaching $50 \%$ as electricity, but not gas, is being decarbonised. A fast and massive decarbonisation of heat supply, requiring substantial investments as well as structural changes during the next decades, will be crucial to meet the UK's net-zero emissions target by 2050 as defined by the Clean Growth Strategy, since other sectors, like aviation, will likely continue to emit greenhouse gases[2]. There are multiple technologies that are capable of delivering heat with near zero greenhouse gas emissions, and multiple criteria against which they need to be selected, but currently there is no consensus on the most appropriate mix of technologies for the UK[1].

Although systems with high shares of renewables have been extensively shown to be viable[3, 4], and appear to offer some advantages over designs mainly relying on nuclear[5] and Carbon Capture and Storage[6], addressing wind and solar supply variations while considering the effects of climate change remains a significant challenge[7]. Meteorology drives a large fraction of the heating and cooling demand in buildings and vehicles, and causes fluctuations in renewable generation, resulting in periods of supply deficit and surplus. Whilst variable renewables can be balanced with storage and interconnectors $[8,9]$, finding low cost combinations of these and of other system components, such as heat pumps, is a complex problem yet to be solved.

Due to its implications across the entire energy system infrastructure, decarbonisation of heat supply must be tackled with a whole system approach, using explicit hourly simulation of the states and technical performance of all major categories of technology that would be needed, and long historical periods of weather data combined with climate change scenarios to model supply and demand. Although this approach is strongly recommended by MetOffice to fill the current modelling gap[7] as an essential tool to designing $100 \%$ renewable and nuclear systems that meet energy demands dynamically existing models focus on limited features of the energy system, have limited temporal and spatial resolution, and neglect endogenous demand modelling. For example, most studies on systems with high shares of variable renewables adopt a low temporal resolution[10-15], which can hinder the model ability to accurately estimate component capacities and system costs. A number of studies only simulate a single year[19, 23-28], and even when multiple years are modelled, these are not contiguous[29, 30]. Very often models for a single country do not include interconnections to a wider geographical area[1721]. Moreover, sector coupling still remains an outstanding challenge to be addressed in model development[10,11] and many models only focus on a single sector, usually electricity, thus decreasing the utilization potential of variable renewable energy sources[16]. Energy demands are often an exogenous input assumption[17, 18, 28, 32-35] (see [36] for a review), sometimes even extracted from historical data without changing their shape or magnitude[32-34]; despite being of paramount importance for understanding future profile [36], dynamic demand modelling is still lacking [37]. Consequently, also the impact of climate change on demands is often neglected in existing energy system models[16-21, 28, 31, 33, 35].

The novelty in the model presented in this study, the Energy Space Time Integrated Model Optimiser (ESTIMO), is the incorporation of all these features: the integration on a continental scale of a sector-coupled, multi-vector, country-resolved

Page $2 / 19$ 
energy system driven by variable renewables and end-use demands modelling at hourly time resolution, over multiple contiguous years of weather data and climate change scenarios. This approach is crucial for a comprehensive understanding of the trade-offs and balances among capacities of variable renewables, stores, and interconnectors. Compared to existing models, ESTIMO: (i) uses 35 years of historic meteorology data, and social patterns for a more consistent and flexible modelling of demands and renewables than models using exogenous data; (ii) has heating and cooling in buildings and electric vehicles, road and maritime transport, and synthetic fuel demands, for better supply and storage capacity estimates than electricity sector models; (iii) has high temporal resolution and horizon for systems designs, providing accurate estimates of storage needs and meteorology-resilient systems; (iv) uses an original algorithm for energy dispatch and international trading for a fuller consideration of interconnection flows than sector-coupled whole energy systems with low spatial resolution.

In this paper we use ESTIMO to simulate and compare zero-emission energy system architectures (ZEESAs) with different heating technology mixes, to provide insights into the technical and economic implications of choices.

Our results show that architectures based on district heating and consumer heat pumps need about four times less electricity per unit of heat output than an electrolytic hydrogen boiler, have a whole system cost about $33 \%$ lower, and produce heat at about half the cost. Moreover, as heat pumps require less electricity than hydrogen, the requisite primary supply could be developed faster and, therefore potentially facilitate a more rapid achievement of the net-zero target and of reduced cumulative emissions.

\section{Results And Discussions}

\subsection{Storage requirements in extreme weather conditions}

To study and compare the implications of the selected heating technologies on the UK whole energy system, we designed and simulated three "core" architectures (see Table 1 and Methods for further details), in which the main heat supply is provided by consumer heat pumps (HP scenario), district heating (DH scenario), or hydrogen boilers (H2 scenario). Since our aim was to find renewables-based zero-emissions energy systems that are resilient to extreme weather events - defined as prolonged periods of high energy demand and low generation at the same time - we simulated those three scenarios using a 3-year time window centred on a "stress year", with 2010 having one of the most stressful meteorology periods between January and February - when the national average wind speed and temperature were $3 \mathrm{~m} / \mathrm{s}$ and $2{ }^{\circ} \mathrm{C}$, respectively - and then in December of the same year, with the same low wind speed and an average temperature of $1^{\circ} \mathrm{C}$. Storage is a crucial component for balancing meteorology-driven variations in renewable supply and demands from hourly to inter-annual temporal scales. As shown in Fig. 1, hourly storage levels in all simulated scenarios exhibit a similar annual seasonality, as stores are discharged during winter and recharged in summer. The heat storage in DH (Fig. 1A), for example, is heavily used in December and January. In winter, the average heat storage output is $15 \mathrm{GW}_{\text {th }}$ and its sum reaches $28 \mathrm{TWh}$, while the summer output averages around $2 \mathrm{GW}_{\text {th }}$. In particular, the storage has a peak output of $154 \mathrm{GW}_{\mathrm{th}}$, with a large discharge of $16 \mathrm{TWh}_{\text {th }}$, lowering the storage level down to $88 \mathrm{GWh}_{\text {th }}$ within 16 days (from 2010-12-17 to 2011-01-03). In the same period, the heat demand reaches $44 \mathrm{TWh}$, with a peak of $186 \mathrm{GW}_{\mathrm{th}}$. This event is the most demanding for storage, as in the previous winter the storage level is down to $7 \mathrm{TWh}_{\mathrm{th}}$, the peak storage output is $137 \mathrm{GW}_{\mathrm{th}}$, while the heat demand peaks at $145 \mathrm{GW}_{\text {th }}$ (i.e. in 2010, heat peak demand was $40 \mathrm{GW}_{\text {th }}$ higher). The output from hydrogen (Fig. 1B) and electricity (Fig. 1C) storage, in the $\mathrm{H} 2$ and HP scenarios respectively, shows a similar pattern to the heat storage in $\mathrm{DH}$. This might be expected as demands and renewable generation are the same in the core scenarios. The storage dynamics during the end of 2010 shows that, given the renewable and interconnection capacities, the total system storage must be of the order of tens of TWh to cover supply deficits during extreme meteorology. In general, the capacities of the different storage types depend on their locations in the energy system, the other system components, and the parameters optimised in the system design. In ESTIMO, the stores are connected at the transmission level and their sizes were manually designed. 


\subsection{The impact of different energy system components on storage need}

To explore the interplay between system components, such as renewable capacity or interconnectors, on storage needs, we created eight zero emission variants of the DH scenario (Table 1 and Methods) in which we offset heat storage size with wind and solar capacities (DH GenLo, DH GenHi, DH PVLo), or interconnectors (DH LinHi), changed the building heat loss parameter ( $\mathrm{DH}$ InsLo, $\mathrm{DH}$ InsHi), and increased the ambient temperature to take into account climate change (DH CChLo, DH $\mathrm{CChHi)}$. After running simulations of these variants between 2009 and 2011, we found that a $50 \%$ reduction of the storage size of the DH core architecture can be balanced by either a 33\% increase of wind and solar generation (DH GenHi) or a $200 \%$ increase of the UK interconnector capacity ( $\mathrm{DH} \mathrm{LinHi})$. On the other hand, a 33\% reduction of renewable generation is balanced by a 100\% increase of the storage size (DH GenLo) (Fig. 2). This trend indicates a non-linear relationship between storage size and renewable supply, as a fractional decrease in renewable would require a greater increase in storage. Likewise, in the scenario with low solar PV (DH PVLo), the higher offshore wind capacity allows less storage, as its minimum level is $3 \mathrm{TWh}$ higher than in the core $\mathrm{DH}$ architecture. These results suggest that $1 \mathrm{GW}$ of installed offshore wind and solar capacity, when not critically low, are functionally equivalent at the margin to about $200 \mathrm{GWh}$ of storage; with an impact of 2.5 times that of solar PV, offshore wind generation which would significantly contribute towards a reduction of storage needs.

In addition to storage size, we analysed how storage output changed with varying renewable capacities, building insulation, and climate change. From our simulations of 2010, we found that the annual heat storage output reaches $86 \mathrm{TWh}_{\text {th }}$ in the DH GenLo scenario and $58 \mathrm{TWh}_{\text {th }}$ in the $\mathrm{DH}$ GenHi scenario, corresponding to a change of $+24 \%$ and $-19 \%$, respectively, compared to the $70 \mathrm{TWh}_{\text {th }}$ of the core $\mathrm{DH}$ architecture, suggesting that each $\mathrm{GW}$ of difference in the renewable capacity changes the delivered storage heat by about $3 \mathrm{TWh}_{\mathrm{th}}$. The scenarios $\mathrm{DH}$ InsHi and $\mathrm{DH}$ InsLo have a lesser impact on heat storage, just $5 \mathrm{TWh}_{\text {th }}$ (i.e. $\sim 6 \%$ of the $\mathrm{DH}$ core scenario), meaning that a change of $1 \%$ in building insulation corresponds to roughly $1 \%$ difference in heat storage output. Compared to the core $\mathrm{DH}$ architecture, we found that storage is also used less in the DH CChLo and DH CChHi scenarios, where the total heat storage output is $20 \%$ and $36 \%$ smaller (56 and $45 \mathrm{TWh}_{\text {th }}$ ) respectively. Therefore, every additional degree in the average ambient temperature reduces storage output by about $10 \%$. The largest difference in terms of peak storage output compared to the $154 \mathrm{GW}_{\mathrm{th}}$ of the core $\mathrm{DH}$ scenario can be found in the DH CChLo and DH CChHi scenarios (143 and $133 \mathrm{GW}_{\mathrm{th}}$, respectively), corresponding to $3 \%$ peak reduction per degree Celsius.

Finally, we analysed the DH derived scenarios in terms of storage dynamics, measured as the fraction of hours that the storage is discharged during the simulation. With respect to the core $\mathrm{DH}$ architecture, which shows an output fraction of $15 \%$, the high generation $\mathrm{DH}$ GenHi scenario has a reduced fraction of $13 \%$, corresponding to a more variable storage level, while the low generation DH GenLo shows a higher fraction of $19 \%$, denoted by a flatter storage pattern (Supplementary Fig. 1). For short time scales, these differences can be estimated as a decrease of $1 \%$ in storage output frequency for each $18 \mathrm{GW}$ of installed renewable capacity.

Overall, our findings suggest that renewable capacity, in particular offshore wind with a projected capacity factor of about $60 \%$, has a greater impact on storage size and usage than any other variable (insulation, PV share, or interconnections), and it is therefore an effective measure to reduce storage need.

\subsection{The role of system storage on long-term time scales}

We evaluated storage capacity and use patterns by simulating the operation of the three core architectures with 35 years (1980-2015) of historical meteorology data. This approach allowed us to analyse relatively rare meteorology, such as periods of low wind and temperature (as in 2010), and to describe the seasonal and the inter-annual variability in storage use. We found that the most frequent output from heat and hydrogen storage is around $20 \mathrm{GW}$ and can balance supply in a wide range of energy deficits, up to $160 \mathrm{GW}$ in winter periods, with an almost linearly decreasing frequency (Fig. 3A). Heat storage output shows a less skewed distribution than the other two storage types, with a higher usage than the hydrogen 
storage at values below $10 \mathrm{GW}$, and a lower peak at $20 \mathrm{GW}$. Electricity storage shows an additional peak for very small outputs, as it is also used to meet short-term small fluctuations of electricity-specific (e.g. appliances, lighting) end-use demand. The distribution of electricity storage output has a shorter range than the other two storage types because the electricity storage size is set to a smaller capacity, due to its high unit cost. An example of the actual temporal distribution of the storage output is given by the DH heat output along the 35 years, aggregated into a single year time (Fig. 3B); storage his usually full, as shown by the weekly median of zero, and is characterised by frequent hourly variations - up to $100 \mathrm{GW}_{\text {th }}$, as indicated by the interquartile range - which are uniformly spread along the year, with a total range between $40 \mathrm{GW}_{\text {th }}$ in summer to $160 \mathrm{GW}_{\text {th }}$ in winter. The storage output values recorded in summer are partially due to mild wind speeds (compared to winter) and to nightly heat demand, resulting from our assumptions on human activity patterns and on the thermostat cut-off temperature set to $20^{\circ} \mathrm{C}$ for space heating demand. As the simulated architectures were manually created, the size of heat and hydrogen storages are not optimised to balance supply exactly; instead, they were slightly oversized to make sure that no biomass or natural gas is consumed during periods of peak heat demand.

These storage output patterns suggest that, regardless of the heating architecture, all storage types would play the same double role: as seasonal back-up with a wide range of output capacities, and as a short-term flexible buffer to balance hourly and small daily supply-demand mismatches, in which the electricity storage would cover the smaller end of the output capacity range. Regarding long-term energy needs, the storage outputs should be in the order of $100 \mathrm{GW}$ to cope with rare very high demand, as indicated by the wide range of the modelled storage output.

\subsection{Annual energy consumption and peak demand}

Together with storage needs, our 2009-2011 simulations also provided valuable insights on end-use energy demand (Supplementary Figs. 2 and 3). During 2010, heat annual consumption and peak demand are, respectively, $540 \mathrm{TWh}_{\text {th }}$ and $186 \mathrm{GW}_{\text {th }}$ in the core $\mathrm{DH}$ architecture; these values are unchanged across all scenarios, except in the building insulation and climate change scenarios. In the DH CChLo, consumption is $478 \mathrm{TWh}_{\mathrm{th}}$, with a peak of $174 \mathrm{GW}_{\mathrm{th}}$, while in the $\mathrm{DH}$ CChHi these quantities are $422 \mathrm{TWh}_{\text {th }}$ and $162 \mathrm{GW}_{\mathrm{th}}$, respectively, suggesting that for each $+1^{\circ} \mathrm{C}$ in annual average ambient temperature, annual heat consumption decreases by $31 \mathrm{TWh}_{\mathrm{th}}(1 \%$ of the consumption in the core $\mathrm{DH})$ while peak demand is reduced by $6 \mathrm{GW}_{\text {th }}$ ( $3 \%$ of the peak demand in the core $\mathrm{DH}$ ). As an additional note, air conditioning demand increases by $100 \%$ in $\mathrm{DH}$ CChLo and by $200 \%$ in $\mathrm{DH}$ CChHi, that is, by $50 \%$ per ${ }^{\circ} \mathrm{C}$. For electric vehicles, the change in annual energy consumption due to climate change is quite small, around $1 \%$ per ${ }^{\circ} \mathrm{C}$, as less cabin heating is nearly balanced by increased cabin cooling in summer, as are the impacts on EV battery and heat pump efficiencies. These results suggest that climate change will have a bigger impact on cooling than on heating demand; this modelling needs refining, but it illustrates the importance of an integrated system modelling approach to evaluate the cumulative impact of different demands on the system.

As the remaining non-heat demands are the same in all scenarios, electricity consumption - inclusive of electricity delivered to consumers, DH heat pumps, electrolysers, and transmission losses - is similar across almost all scenarios (Fig. 4), except for the hydrogen boiler and Climate change scenarios (Supplementary Table 1). In the core $\mathrm{H} 2$ architecture, the total electricity consumption is about double that of the architectures using heat pumps (which have an average COP of 300$450 \%$ ), because the overall efficiency of the hydrogen supply chain is only about $70 \%$ (assuming $80 \%$ electrolysis efficiency and $85 \%$ boiler efficiency). Therefore, the $\mathrm{H} 2$ architecture uses 4 to 6 times more electricity per heat output than the core HP and $\mathrm{DH}$ architectures. In the $\mathrm{DH}$ CCh scenarios, electricity consumption is reduced by about $2.5 \%$ per degree increase in annual mean ambient temperature, since the heat demand is less than the DH scenario.

The highest peak of delivered electricity to all consumers of $156 \mathrm{GW}_{\mathrm{e}}$ occurs in the core HP scenario, in which the peak input to consumer heat pumps is $49 \mathrm{GW}$, converted to $131 \mathrm{GW}_{\text {th }}$ of heat at an average COP of 2.7 (Supplementary Fig. 4). On the supply side, the peak renewable and nuclear generation is $270 \mathrm{GW}_{\mathrm{e}}$ and sufficient network capacity is needed to utilise some of the surpluses. In the H2 scenario, the delivered peak $\left(136 \mathrm{GW}_{\mathrm{e}}\right.$ ) is lower than the HP case, but the overall peak on the UK 
transmission network is the highest, $325 \mathrm{GW}_{\mathrm{e}}$, mainly because of the electricity input to the electrolysers, which reaches 250 $\mathrm{GW}_{\mathrm{e}}$. Around $40-50 \%$ of electricity generation ( $500 \mathrm{TWh}$ ) is spilled annually across all scenarios, when supply is greater than demand and the surplus cannot be stored or exported because there is no spare capacity. Spillage occurs on average about $30 \%$ of annual hours and is distributed quite uniformly across each year of the simulations. Among the core architectures, spillage is $50 \%$ in the $\mathrm{H} 2$ and $\mathrm{HP}$ scenarios, and $46 \%$ in $\mathrm{DH}$; in the derived $\mathrm{DH}$ scenarios, spillage is the lowest in DH GenLo (41\%), and reaches the maximum of $50 \%$ in DH GenHi and DH CChHi (Supplementary Fig. 5). Altogether, our findings highlight that the hydrogen architecture would require a significant increase in renewable generation and network transmission capacities with respect to the other scenarios, due to its considerable electricity demand.

\subsection{Whole system and heating costs}

The component capacities drive the dominant fixed capital and O\&M costs, with variable O\&M small, and no fuel costs in the scenarios. We annuitized capital costs, and aggregated annual system costs by consumer, intermediate and primary energy categories (Fig. 5). In terms of consumer capital cost, the HP scenario is the most expensive (23 G£/a, 57\% higher than DH and $\sim 30 \%$ higher than $\mathrm{H} 2$ ); similarly, electricity storage and network costs are higher in the HP (19.6 G£/a) than in the DH (+ $42 \%)$ and $\mathrm{H} 2(+16 \%)$ architectures. Storage and network account for $22.8 \mathrm{G} £ / \mathrm{a}$ in $\mathrm{DH}$, and $20.9 \mathrm{G} £ / \mathrm{a}$ in $\mathrm{H} 2$. In total, intermediate technologies amount to $29.3 \mathrm{G}$ /a in HP, $27.8 \mathrm{G}$ /a in $\mathrm{DH}$, and $37.9 \mathrm{G} £ / \mathrm{a}$ in $\mathrm{H} 2$. With regards to renewables, the $\mathrm{H} 2$ architecture is the costliest ( $46 \mathrm{G} £ / \mathrm{a}$ ), because of the greater need for primary energy. This results in the highest total system cost $(102.6 \mathrm{G} £ /$ a), which is 26\% more expensive than HP and $\sim 40 \%$ higher with respect to DH (Supplementary Table 2). Specifically, both capital and O\&M system costs are higher in the $\mathrm{H} 2$ architecture than in the other two core scenarios (Supplementary Table 3).

Although total heat-related costs for consumer and intermediate heating technologies are similar across the core architectures (around $33 \mathrm{G} £ / \mathrm{a}$ ), in HP these are mostly allocated to consumers (23G£/a), in DH to district heating schemes (23G£/a), and in $\mathrm{H} 2$ equally distributed between consumer and intermediate conversion (Fig. 6). However, $\mathrm{H} 2$ incurs a $270 \%$ higher cost for electricity supply for heat $(52 \mathrm{G} £ / \mathrm{a})$ than the other core scenarios ( $14 \mathrm{G} £ / \mathrm{a})$, because of its higher electricity consumption ( $58 \%$, as opposed to $24 \%$ in $\mathrm{DH}$ and $\mathrm{HP}$ ) necessary for hydrogen production. Consequently, the total heat cost in $\mathrm{H} 2$ reaches $83 \mathrm{G} £ / \mathrm{a}$, which corresponds to $81 \%$ of the total system costs, which is more than the $47 \mathrm{G} £ / a$ of $\mathrm{DH}$ and $\mathrm{HP}$ (representing about $60 \%$ of the total system cost) (Supplementary Table 4). These costs correspond to an average cost for heating of $17.8 \mathrm{p} / \mathrm{kWh}$ in $\mathrm{H} 2$, and around $10.2 \mathrm{p} / \mathrm{kWh}$ in $\mathrm{DH}$ and HP; and for electricity of $7.3 \mathrm{p} / \mathrm{kWh}$ in H2, 7.9 p/kWh in DH, and the highest cost of $9.4 \mathrm{p} / \mathrm{kWh}$ in HP.

Overall, we found that ZEESAs costs are predominantly due to capital costs with O\&M costs accounting for $34 \%$ of total costs, which are the highest in the $\mathrm{H} 2$ architecture due to high electricity demand; system costs are similar for the DH and HP scenarios, although in HP they mostly bear on the consumer side.

\subsection{Conclusions}

In this study, we used a methodology that combines a meteorology-driven whole system modelling approach with hourly simulations to understand the requirements and operation of future ZEESAs for the United Kingdom. We focussed on scenarios for heating, one of the most challenging energy consuming sectors to decarbonise. Before describing the advantages of our study, there are a couple of caveats that must be considered. The architectures were designed manually, though informed by other optimisation work. To reduce computational time, we opted for a simplified but functional representation of the international European network through a star topology, to simulate the electricity flows among countries. The algorithm controlling hourly energy flows within a node and between nodes aims to maximise the use of zero emission supplies for a given system design. This algorithm is one of the most complex parts of the model.

One of the main advantages of ESTIMO is to model both demand and supply using long-term historical weather data, thus providing valuable insights on the long-term dynamics of renewable-based systems that many investment modelling approaches (e.g. the TIMES family of models) cannot yield accurately. We demonstrate the importance of using long time 
simulations for capturing meteorology and climate variability and quantifying impacts on heat demands and storage; our results indicate that there is an inverse linear relationship between increasing ambient temperature and energy consumption for heating.

Furthermore, our integrated system approach allows to evaluate the implications of components on the whole system and, therefore, to estimate the technology requirements accurately. In particular, we show that future systems will need to store energy in the order of tens of TWh to cope with demand driven by extreme weather events; storage has a dual role to meet small demands frequently and high peaks more rarely. Moreover, we highlight the non-linear inverse relationship between renewable capacities and storage size, with the balance between these depending on the relative costs. We analysed 35 years of weather data, but there may be more extreme meteorology in the future and to provide resilience against this, options such demand reduction or generators using stored fossil fuels or scarce biomass could be deployed. However, if fossil fuels, even with carbon capture and storage, were used regularly then emissions would have to be balanced with environmental carbon capture.

We have calculated the costs of all components, but there are uncertainties particularly relating to network costs: for hydrogen there no large-scale networks and consumer adoption. A key insight of our study of heat decarbonisation within a zero-emission energy system is that heat pump technology represents the most cost-effective solution, thanks to its efficiency and therefore low electricity consumption. An additional advantage is they can be reversible and used for cooling. District heating has lower heat costs than consumer heat pumps, because of its scale economies, and wider role in system management. In contrast, a heating with electrolytic hydrogen boilers leads to higher total system costs and to heat related costs than architectures dominated by consumer or district heat pumps due to its greater requirements for renewable capacity. This means a faster rate of renewable installation is required, with implications for the difficulty of reaching the netzero target mandated by the UK Government (Climate Change Act 2008, Order 2019). Technology improvements can be expected in the future in terms of cost and performance. Some future costs are very uncertain, particularly for batteries, wind and solar generators: the past decade's reduction of $50-80 \%$ in the costs of these, with further reductions forecast. The capacity factors of new, larger offshore wind turbines, currently estimated to be around $60 \%$, have a large impact on storage need. Our results show that increasing UK interconnections to Europe would reduce storage need.

This is rapidly changing the optimum least cost balance between technologies. The consequent reduction in heat pump heat costs reduce the cost-effectiveness of deep building retrofit. Consumer heat pumps and hydrogen are inflexible in that there is only one last conversion pathway to heat. District heating, in contrast, has a range of possible heat production components - heat pumps, storage, CHP, boilers, solar and geothermal - which mix can be changed hour by hour and is evolvable as the mix of component capacities can be changed across the years without physical impact on consumers. Moreover, district heating can facilitate competition between heat providers and thereby reduce costs for consumers[38].

To conclude, our findings indicate that a zero-emission energy system for the UK based on renewables would need efficient technologies, such as heat pumps, as well as system stores, to resiliently manage emissions during rare meteorology periods. Reducing emissions from heat is a high priority since aviation and some industrial processes are more difficult to decarbonise. The speed of implementation is important to reduce emissions as rapidly as possible and thereby the cumulative emission to 2050. We have not reported here the required rates of installation of the various components to achieve net zero by 2050 , nor we have modelled the required social capacity (labour force, financing) to meet installation rates. These data would be needed to detail explicit policies to reach targets, such as mandating replacing gas boilers with heat pumps or renewable capacity auctions (Supplementary notes 2). Future developments of ESTIMO will prioritise the addition of: (1) district cooling, to explore its costs and synergies with heating; (2) sustainable fuel supply for aviation, to calculate the sector emissions and primary energy demand; (3) carbon capture and storage, to provide a carbon feedstock for synthetic fuels and to balance residual emissions; (4) an optimisation algorithm. These improvements will enable us to explore a larger set of scenarios and address additional questions, for example assessing the consequences of undersized storages on biofuels consumption or evaluating the trade space of alternative architectures. 


\section{Methods}

\subsection{ESTIMO model structure}

The Energy-Space-Time Integrated Model Optimiser (ESTIMO) uses a novel whole system approach to meet greenhouse gas $(\mathrm{GHG})$ targets while meeting the hourly end use energy demands of multi-regional energy systems. ESTIMO uses long time series of weather data and social activity patterns to consistently model demands and renewable supplies, in an integrated system with flexible technologies, storage, and interconnections. Other outputs from ESTIMO are weather pattern distributions, annual and maximum energy flows, storage usage, energy losses, as well as capital and operating expenditures at national and system level. ESTIMO can be used to perform hourly simulations across multiple contiguous years with a high-resolution modelling approach that is essential to accurately simulate energy systems with a high share of renewables and yet resilient to extreme weather variations, complementing models with lower temporal resolution such as the TIMES family. The international scale of ESTIMO facilitates a precise assessment of the balance between interconnector trade, storage, and renewable capacities.

ESTIMO concurrently models the systems of several different regions or nodes; for this study, five nodes comprising the UK and four aggregate European regions. ESTIMO uses a star topology to represent a network of nodes connected to a central virtual node trading electricity. The star network enables fast complex non-linear and optimal flow simulation as compared to if nodes are multiply connected in a mesh. The location of the central node is the total consumption-weighted average of the other nodes' positions, which is the geometrical centre of the aggregated countries. These approximations are used to estimate the interconnector lengths, efficiencies, and costs of the real-world mesh networks.

The model's geographical boundaries are solely determined by the input data, which can range from a single country to the whole world. The link capacities are the summed capacities of the national interconnectors stemming from the country's node. Each node (Supplementary Fig. 6) represents a self-contained whole energy system with sectorial (residential, services, industry, and transport) end use demand, supply, conversion technologies, storage, and interconnections as single elements, e.g. single grid storage or residential space heating demand. End use demand are appliances, lighting, space heating, water heating, cooking, process heat, vehicles, trains, and ships. Primary energy sources are wind, solar, hydro, geothermal, nuclear, natural gas, and biomass. Demand and supply are internally connected in each node via uncapped electricity, heat, hydrogen, and ammonia networks, which include stores (grid, heat in district heating schemes, electric vehicle batteries, hydrogen, ammonia) and are coupled through conversion subsystems. Heating and cooling demands are met with consumer technologies - heat pumps, hydrogen or gas boilers, electric heater, and district heating with heat pumps, CHP, and boilers. The district CHP and boilers are fuelled with ammonia, biomass, or natural gas. Supply, demand, and conversion technologies are defined by average capacities, efficiencies, lifetime, capital costs, and operation and maintenance costs, as well as $\mathrm{CO}_{2}, \mathrm{NO}_{x}, \mathrm{CH}_{4}, \mathrm{~N}_{2} \mathrm{O}$, and particles emissions, all of which depend on the technology unit sizes.

\subsection{ESTIMO algorithm}

Starting from the architecture defined by the input historical national data, ESTIMO uses interpolation to evolve this initial energy system towards the input target architecture (e.g. for the year 2050), with user-defined steps (e.g. 10 years). The magnitude and direction of the change in the system variables are determined by the policy scenarios, whilst their trend is defined by transitions characterised with an interpolation function (e.g. linear or sinusoidal), a starting delay (i.e. 5 years) and the rate required to achieve the desired change (e.g. 35 years to replace all fossil fuel-based vehicles with electric vehicles. These transitions do not include technology stock details and the technicalities of network expansion. The scenarios, based on the Society Energy Environment Scenario model (SEEScen)[39], specify changes in consumer behaviour, demand management, share of renewable supply and clean appliances, technology efficiencies, nuclear and interconnector capacities. Assumptions on changes in population, household number, average heating and cooling temperature thermostat set points, and maximum policy impact are provided exogenously. 
For each step year of system evolution, ESTIMO simulates the whole energy system at each hour of the input meteorology time series - consisting of temperature, wind speed, and solar irradiance - which can range from just a few hours to several decades. Climate change can be introduced in the simulation by defining an annual or seasonal temperature variation that is applied to the historic time series. ESTIMO concurrently simulates each node and the trade among them through an operational algorithm that dynamically changes the operation of components according to the availability of renewables, storage, and imports to maximise the use of zero emission energy and thereby minimise the consumption of constrained biomass and natural gas. Wind and solar photovoltaic generation are calculated as previously described in Park et al.[40] using the state-of-the-art global climate reanalysis dataset Modern-Era Retrospective analysis for Research and Applications (MERRA)[41].

Demand and energy flow equations are based on the DynEMo model[42] and are briefly summarised here. Weatherdependent heating and cooling demand for buildings are calculated by multiplying the difference between ambient and internal temperatures to the national average specific heat loss of buildings (taken from the EU Building Database[43]), then subtracting from the result internal gains - people, appliances, insolation - and multiplying this by the activity pattern. Weather-independent demands are calculated by multiplying each activity pattern for the corresponding annual average demand. Electric vehicle and rail demand are temperature-weighted to consider heating and cooling loads. In particular, electric vehicle charging is adjusted for the day-ahead average ambient temperature to balance battery performance variations. End use activity patterns are hourly indices representing the average usage of appliances and vehicles in each day and month[42].

ESTIMO's dispatch algorithm has three main stages. First, the model calculates useful energy demands for each node. Then, these are allocated to technology shares for estimating the energy deliveries, which are aggregated by vectors and met with renewable electricity and heat from district heating (Supplementary Fig. 7). After this step, stores are either used to meet any residual demand, or recharged if any generation surplus is present (storage at consumer premises, such as hot water tanks or batteries, and vehicle-to-grid technology are not yet considered). In the latter case, electricity storage is prioritised over heat and chemical storages. Electric vehicle batteries are charged daily during the night by the expected demand of the day ahead.

Second, the model equally distributes nodes' surplus electricity to nodes with residual electricity demand, and then to nodes with remaining storage capacity.

Third, ESTIMO meets any residual demand in each node with dispatchable supply in that node. Heat supply in district heating is first provided by heat pumps (using electricity from the grid), then storage, combining heat from CHP and from heat pumps powered with the CHP itself, and finally by a boiler. Both CHP and boiler first consume ammonia and then biomass (Supplementary Fig. 6). Electricity supply can come from CHP, if the district heat storage has spare capacity, or from a generic gas power station.

A node's energy network capacities are determined by three components: the peak energy flows, and the power and energy capacities of the stores and generators.

Once the simulation for a year is concluded, ESTIMO calculates annuitized capital and operational costs of the installed capacity for each technology included in the scenario. The costs of energy efficiency (insulation and equipment) are not calculated in ESTIMO as this requires the detailed stock modelling of deployment programmes and is beyond the current scope of the model. The model returns: (1) tables and charts for all variables along the system evolution; (2) a map showing the star network and the aggregated countries; (3) the hourly time series - as CSV and charts - of all the simulated variables (e.g. useful demand, delivered energy, storage in/out and level, renewable generation, conversion and transmission losses, import/export, primary and secondary energy supply) and of the input weather data; (4) a table containing annual peak and total energy flows, and annuitized capital and operational costs. ESTIMO has been calibrated on the UK's 2015 weather data and annual energy statistics[44] and validated against 2016 data. Simulated delivered energy annual flows were within 90- 
95\% of the reference statistics. ESTIMO is written in Python 3 and leverages the packages Pandas[45] for I/O operations, NumPy[46] for calculations, and Holoviews/Bokeh for interactive data visualisation.

\subsection{Energy system and scenarios set-up}

As we aimed to explore UK architectures that are resilient, i.e. meeting demand with zero emissions, to extreme weather conditions, we looked for the greatest difference between demand and renewable supply in the UK along the 35 years of weather data (1980-2015) extracted from MERRA. We identified 2010 as the best candidate "stress year", because it included winter periods with the greatest difference between cumulative wind generation and heat demand (for which we used ambient temperature as a proxy). We decided to perform the simulations of each step year along three contiguous years of weather data, between 2009 and 2011, both to establish system starting state (storage levels) and initial transients on the results and to evaluate the consequences of 2010/11 weather conditions on the following year.

The modelled regional energy system covered 28 European countries aggregated in 4 nodes, based on the IPCC climate classification[47], plus the UK as a single node.

The main heat supply of the three "core" scenarios (Table 1) is provided by heat pumps (HP), district heating (DH), or hydrogen boilers $(\mathrm{H} 2)$, with the focus of comparing the implications of these heating technologies on the UK whole energy system. All system components are kept equal across the three core architectures, except for heat supply, which is subdivided into: $70 \%$ consumer heat pump and $30 \%$ district heating for the core HP; $70 \%$ district heating and $30 \%$ consumer heat pump for the core $\mathrm{DH} ; 70 \%$ boiler using electrolytic hydrogen and $30 \%$ consumer heat pumps for the core $\mathrm{H} 2$. To create the eight "variant" district heating scenarios with zero emissions (Table 1) we modified the core architectures by: (i) balancing heat storage size with wind and solar capacities (DH GenLo, DH GenHi, DH PVLo), and interconnectors (DH LinHi); (ii) changing the building heat loss parameter ( $\mathrm{DH}$ InsLo, DH InsHi); (iii) increasing the ambient temperature to take into account climate change (DH CChLo, DH CChHi). These scenarios were designed by manually balancing the storage and generation capacity, to give zero biomass and gas consumption. In particular, we opted to keep electricity storage size as small as possible since it has higher costs than other storage types, though a minimum is needed to meet electricity-specific demands[48]. We assumed 25-53 GW of UK interconnector capacity[49] in DH LinHi, +2/+4 in DH CCh[50] A modest +/-5\% variation in building stock heat loss factor is assumed. Most of the current buildings will exist in 30 years' time and it is problematic for technical, financing and disruption reasons to retrofit more than moderate efficiency to existing buildings, as the past half century has shown. The population and household numbers are projected to increase in the UK which will counterbalance efficiency gains. 
Table 1

Scenarios for UK zero emissions energy systems.

\begin{tabular}{|c|c|c|c|c|c|c|c|c|c|c|c|}
\hline Variable & $\mathrm{DH}$ & HP & $\mathrm{H} 2$ & $\begin{array}{l}\text { DH } \\
\text { GenHi }\end{array}$ & $\begin{array}{l}\text { DH } \\
\text { GenLo }\end{array}$ & $\begin{array}{l}\text { DH } \\
\text { PVLo }\end{array}$ & $\begin{array}{l}\mathrm{DH} \\
\text { LinHi }\end{array}$ & $\begin{array}{l}\text { DH } \\
\text { InsLo }\end{array}$ & $\begin{array}{l}\mathrm{DH} \\
\text { InsHi }\end{array}$ & $\begin{array}{l}\text { DH } \\
\text { CChLo }\end{array}$ & $\begin{array}{l}\mathrm{DH} \\
\mathrm{CChHi}\end{array}$ \\
\hline HP share (\%) & 30 & 70 & 30 & 30 & 30 & 30 & 30 & 30 & 30 & 30 & 30 \\
\hline DH share (\%) & 70 & 30 & 0 & 70 & 70 & 70 & 70 & 70 & 70 & 70 & 70 \\
\hline $\begin{array}{l}\text { H2 boiler } \\
\text { share (\%) }\end{array}$ & 0 & 0 & 70 & 0 & 0 & 0 & 0 & 0 & 0 & 0 & 0 \\
\hline $\begin{array}{l}\text { Storage H2 } \\
\text { (GWh) }\end{array}$ & 0 & 0 & 15737 & 0 & 0 & 0 & 0 & 0 & 0 & 0 & 0 \\
\hline $\begin{array}{l}\text { Storage grid } \\
\text { (GWh) }\end{array}$ & 2300 & 3020 & 2275 & 1150 & 4599 & 2300 & 1150 & 2300 & 2300 & 2300 & 2300 \\
\hline $\begin{array}{l}\text { DH storage } \\
\text { heat (GWh) }\end{array}$ & 13869 & 10489 & 0 & 7013 & 27739 & 13869 & 7013 & 13869 & 13869 & 13869 & 13869 \\
\hline $\begin{array}{l}\text { PV capacity } \\
\text { (GW) }\end{array}$ & 105 & 114 & 173 & 131 & 79 & 79 & 105 & 105 & 105 & 105 & 105 \\
\hline $\begin{array}{l}\text { Wind onshore } \\
\text { capacity (GW) }\end{array}$ & 52 & 57 & 86 & 52 & 52 & 52 & 52 & 52 & 52 & 52 & 52 \\
\hline $\begin{array}{l}\text { Wind offshore } \\
\text { capacity (GW) }\end{array}$ & 136 & 148 & 277 & 147 & 126 & 147 & 136 & 136 & 136 & 136 & 136 \\
\hline $\begin{array}{l}\text { Interconnector } \\
\text { capacities UK } \\
\text { (GW) }\end{array}$ & 25 & 25 & 25 & 25 & 25 & 25 & 53 & 25 & 25 & 25 & 25 \\
\hline $\begin{array}{l}\text { Building heat } \\
\text { loss (\%) }\end{array}$ & -10 & -10 & -10 & -10 & -10 & -10 & -10 & -5 & -15 & -10 & -10 \\
\hline $\begin{array}{l}\text { T mean } \\
\text { annual } \\
\text { change }\left({ }^{\circ} \mathrm{C}\right)\end{array}$ & 0 & 0 & 0 & 0 & 0 & 0 & 0 & 0 & 0 & +2 & +4 \\
\hline
\end{tabular}

Each storage type is considered as connected at the transmission level (thus, consumer storage is excluded). Hybrid systems combining multiple options, such as combined heat pump/boiler, are outside the scope of this study. Biomass is assumed to be reserved for aviation, though it is interesting that the major current renewable is biomass storage for the Drax power station. Geothermal and solar heat are not considered. Nuclear capacity in the UK is set to $3 \mathrm{GW}$, as we assume that only Hinkley Point $\mathrm{C}$ will be operational in 2050. System components not included in this work include aviation fuelling, district cooling, and consumer storage. It is not anticipated that including these will substantially change the overall system design and the relative costs of the heat shares, except that to provide cooling, consumer and DH heat pumps would have to be reversible, and HP would have to be added alongside $\mathrm{H} 2$ boilers at additional cost.

We assumed that population growth and concomitant increases in building stocks are largely balanced by improvements in efficiency, so the heat demand simulated using 2009-2011 weather is close to the estimated UK heat demand in 2019. A total electric vehicle battery capacity of $1158 \mathrm{GWh}$ is assumed for all architectures, nominally representing a fleet of 40 million of vehicles with a $30 \mathrm{kWh}$ battery each. Vehicle to grid technology is not considered in this study. The use of natural gas or other fossil fuels to make hydrogen is excluded because, even considering Carbon Capture and Storage, their GHG emissions would have to be balanced by atmospheric $\mathrm{CO}_{2}$ removal, such as with Direct Air Capture and Storage (DACS) technologies, with uncertain costs and environmental impacts.

Data on technology attributes are mainly taken from the Danish Technology Catalogue[51] (Supplementary Note 1 and Supplementary Table 5) for several reasons, this dataset: is consistent and comprehensive, is based on mature supply chain 
and regulatory structure, includes small and large capacity units to account for efficiency and cost economies of scale scale - i.e. large devices have higher efficiency and lower unit cost than small ones -, and provides estimates of future performance and costs. Heat pumps considered in the model only provide heat and are assumed to be air-sourced; their Coefficient of Performance (COP) is calculated as a fraction of the ideal Carnot efficiency and changes with technology size. We have assumed that systems deployed in the 2040s will achieve a significantly improved part load performance[52]. The capital costs are annuitized at 5\%/a using technology lifetimes. The costs of upgrading the high voltage transmission networks (heat, electricity, hydrogen) are assumed proportional to peak flows. The distribution network costs are assumed to increase proportionally with the number of connected users (see Supplementary Fig. 8). Both transmission and distribution costs are very uncertain as they depend on existing capacities, fixed costs, route length and so on.

\section{References}

1. Clean Growth - Transforming Heating. 2018.

2. Climate Change Committee. Net Zero - The UK's contribution tostopping global warming. 2019.

3. Hooker-Stroud A, James P, Kellner T, Allen P. Toward understanding the challenges and opportunities in managing hourly variability in a 100\% renewable energy system for the UK. Carbon Manag 2014.

https://doi.org/10.1080/17583004.2015.1024955.

4. Brown TW, Bischof-Niemz T, Blok K, Breyer C, Lund H, Mathiesen B V. Response to 'Burden of proof: A comprehensive review of the feasibility of 100\% renewable-electricity systems.' Renew Sustain Energy Rev 2018;92:834-47. https://doi.org/10.1016/j.rser.2018.04.113.

5. Sovacool BK, Schmid P, Stirling A, Walter G, MacKerron G. Differences in carbon emissions reduction between countries pursuing renewable electricity versus nuclear power. Nat Energy 2020. https://doi.org/10.1038/s41560-020-00696-3.

6. Sgouridis S, Carbajales-Dale M, Csala D, Chiesa M, Bardi U. Comparative net energy analysis of renewable electricity and carbon capture and storage. Nat Energy 2019. https://doi.org/10.1038/s41560-019-0365-7.

7. Dawkins LC. Weather and climate change risks in a highly renewable UK energy system: literature review. 2019.

8. Gallo Cassarino T, Sharp E, Barrett M. The impact of social and weather drivers on the historical electricity demand in Europe. Appl Energy 2018;229:176-85. https://doi.org/10.1016/j.apenergy.2018.07.108.

9. Steinke F, Wolfrum P, Hoffmann C. Grid vs. storage in a 100\% renewable Europe. Renew Energy 2013. https://doi.org/10.1016/j.renene.2012.07.044.

10. Prina MG, Manzolini G, Moser D, Nastasi B, Sparber W. Classification and challenges of bottom-up energy system models - A review. Renew Sustain Energy Rev 2020;129:109917. https://doi.org/10.1016/j.rser.2020.109917.

11. Ringkjøb HK, Haugan PM, Solbrekke IM. A review of modelling tools for energy and electricity systems with large shares of variable renewables. Renew Sustain Energy Rev 2018;96:440-59. https://doi.org/10.1016/j.rser.2018.08.002.

12. Poncelet K, Delarue E, Six D, Duerinck J, D'haeseleer W. Impact of the level of temporal and operational detail in energysystem planning models. Appl Energy 2016. https://doi.org/10.1016/j.apenergy.2015.10.100.

13. Deane JP, Drayton G, Ó Gallachóir BP. The impact of sub-hourly modelling in power systems with significant levels of renewable generation. Appl Energy 2014;113:152-8. https://doi.org/10.1016/j.apenergy.2013.07.027.

14. Deane JP, Chiodi A, Gargiulo M, Ó Gallachóir BP. Soft-linking of a power systems model to an energy systems model. Energy 2012;42:303-12. https://doi.org/10.1016/j.energy.2012.03.052.

15. Haydt G, Leal V, Pina A, Silva CA. The relevance of the energy resource dynamics in the mid/long-term energy planning models. Renew Energy 2011;36:3068-74. https://doi.org/10.1016/j.renene.2011.03.028.

16. Mathiesen B V., Lund H, Connolly D, Wenzel H, Ostergaard PA, Möller B, et al. Smart Energy Systems for coherent $100 \%$ renewable energy and transport solutions. Appl Energy 2015;145:139-54.

https://doi.org/10.1016/j.apenergy.2015.01.075.

Page $12 / 19$ 
17. Staffell I, Pfenninger S. The increasing impact of weather on electricity supply and demand. Energy 2018;145:65-78. https://doi.org/10.1016/j.energy.2017.12.051.

18. Zeyringer M, Price J, Fais B, Li PH, Sharp E. Designing low-carbon power systems for Great Britain in 2050 that are robust to the spatiotemporal and inter-annual variability of weather. Nat Energy 2018;3:395-403. https://doi.org/10.1038/s41560-018-0128-x.

19. Bobmann T, Staffell I. The shape of future electricity demand: Exploring load curves in 2050s Germany and Britain. Energy 2015;90:1317-33. https://doi.org/10.1016/j.energy.2015.06.082.

20. Palzer A, Henning HM. A comprehensive model for the German electricity and heat sector in a future energy system with a dominant contribution from renewable energy technologies - Part II: Results. Renew Sustain Energy Rev 2014;30:1019-34. https://doi.org/10.1016/j.rser.2013.11.032.

21. Connolly D, Lund H, Mathiesen B V. Smart Energy Europe: The technical and economic impact of one potential $100 \%$ renewable energy scenario for the European Union. Renew Sustain Energy Rev 2016. https://doi.org/10.1016/j.rser.2016.02.025.

22. Hall LMH, Buckley AR. A review of energy systems models in the UK: Prevalent usage and categorisation. Appl Energy 2016;169:607-28. https://doi.org/10.1016/J.APENERGY.2016.02.044.

23. MacDonald AE, Clack CTM, Alexander A, Dunbar A, Wilczak J, Xie Y. Future cost-competitive electricity systems and their impact on US CO2 emissions. Nat Clim Chang 2016;6:526-31. https://doi.org/10.1038/nclimate2921.

24. Frew BA, Becker S, Dvorak MJ, Andresen GB, Jacobson MZ. Flexibility mechanisms and pathways to a highly renewable US electricity future. Energy 2016;101:65-78. https://doi.org/10.1016/j.energy.2016.01.079.

25. Pfenninger S, Keirstead J. Renewables, nuclear, or fossil fuels? Scenarios for Great Britain's power system considering costs, emissions and energy security. Appl Energy 2015;152:83-93. https://doi.org/10.1016/j.apenergy.2015.04.102.

26. Mills AD, Wiser RH. Strategies to mitigate declines in the economic value of wind and solar at high penetration in California. Appl Energy 2015;147:269-78. https://doi.org/10.1016/j.apenergy.2015.03.014.

27. Nelson J, Johnston J, Mileva A, Fripp M, Hoffman I, Petros-Good A, et al. High-resolution modeling of the western North American power system demonstrates low-cost and low-carbon futures. Energy Policy 2012;43:436-47. https://doi.org/10.1016/j.enpol.2012.01.031.

28. Brown T, Schlachtberger D, Kies A, Schramm S, Greiner M. Synergies of sector coupling and transmission reinforcement in a cost-optimised, highly renewable European energy system. Energy 2018;160:720-39.

https://doi.org/10.1016/j.energy.2018.06.222.

29. Pfenninger S. Dealing with multiple decades of hourly wind and PV time series in energy models: A comparison of methods to reduce time resolution and the planning implications of inter-annual variability. Appl Energy 2017;197:1-13. https://doi.org/10.1016/j.apenergy.2017.03.051.

30. Dubilly A-L, Fournier L, Chiche A, Faure N, Bardet R, Alais J-C, et al. A 100\% renewable electricity mix? Analyses and optimisations Testing the boundaries of renewable energy-based electricity development in metropolitan France by 2050. 2016.

31. Schmidt J, Cancella R, Pereira AO. An optimal mix of solar PV, wind and hydro power for a low-carbon electricity supply in Brazil. Renew Energy 2016;85:137-47. https://doi.org/10.1016/j.renene.2015.06.010.

32. Schlott M, Kies A, Brown T, Schramm S, Greiner M. The impact of climate change on a cost-optimal highly renewable European electricity network. Appl Energy 2018;230:1645-59. https://doi.org/10.1016/j.apenergy.2018.09.084.

33. Redondo PD, Van Vliet O. Modelling the Energy Future of Switzerland after the Phase out of Nuclear Power Plants. Energy Procedia, vol. 76, Elsevier Ltd; 2015, p. 49-58. https://doi.org/10.1016/j.egypro.2015.07.843.

34. Kiviluoma J, Meibom P. Methodology for modelling plug-in electric vehicles in the power system and cost estimates for a system with either smart or dumb electric vehicles. Energy 2011;36:1758-67.

https://doi.org/10.1016/j.energy.2010.12.053.

Page $13 / 19$ 
35. Pavičević M, Mangipinto A, Nijs W, Lombardi F, Kavvadias K, Jiménez Navarro JP, et al. The potential of sector coupling in future European energy systems: Soft linking between the Dispa-SET and JRC-EU-TIMES models. Appl Energy 2020;267:115100. https://doi.org/10.1016/j.apenergy.2020.115100.

36. Chang M, Thellufsen JZ, Zakeri B, Pickering B, Pfenninger S, Lund H, et al. Trends in tools and approaches for modelling the energy transition. Appl Energy 2021;290:116731. https://doi.org/10.1016/j.apenergy.2021.116731.

37. Savvidis G, Siala K, Weissbart C, Schmidt L, Borggrefe F, Kumar S, et al. The gap between energy policy challenges and model capabilities. Energy Policy 2019;125:503-20. https://doi.org/10.1016/j.enpol.2018.10.033.

38. Liu W, Klip D, Zappa W, Jelles S, Kramer GJ, van den Broek M. The marginal-cost pricing for a competitive wholesale district heating market: A case study in the Netherlands. Energy 2019;189:116367.

https://doi.org/10.1016/j.energy.2019.116367.

39. Barrett M. Low Emission Energy Scenarios for the European Union. Stockholm: 2008.

40. Park M, Barrett M, Gallo Cassarino T. Assessment of future renewable energy scenarios in South Korea based on costs, emissions and weather-driven hourly simulation. Renew Energy 2019;143. https://doi.org/10.1016/j.renene.2019.05.094.

41. Rienecker MM, Suarez MJ, Gelaro R, Todling R, Bacmeister J, Liu E, et al. MERRA: NASA's Modern-Era Retrospective Analysis for Research and Applications. J Clim 2011;24:3624-48. https://doi.org/10.1175/JCLI-D-11-00015.1.

42. Barrett M, Spataru C. DynEMo: A Dynamic Energy Model for the Exploration of Energy, Society and Environment. Proc UKSim-AMSS 17th Int Conf Comput Model Simulation, UKSim 2015 2016:255-60. https://doi.org/10.1109/UKSim.2015.104.

43. European Commisson. EU Building Database n.d. https://ec.europa.eu/energy/eu-buildings-database_en.

44. BEIS. Energy Consumption in the UK (ECUK). 2020.

45. McKinney W. Data Structures for Statistical Computing in Python. Proc. 9th Python Sci. Conf., 2010. https://doi.org/10.25080/majora-92bf1922-00a.

46. Harris CR, Millman KJ, van der Walt SJ, Gommers R, Virtanen P, Cournapeau D, et al. Array programming with NumPy. Nature 2020. https://doi.org/10.1038/s41586-020-2649-2.

47. Metzger MJ, Bunce RGH, Jongman RHG, Mücher CA, Watkins JW. A climatic stratification of the environment of Europe. Glob Ecol Biogeogr 2005. https://doi.org/10.1111/j.1466-822X.2005.00190.x.

48. Lund H, Østergaard PA, Connolly D, Ridjan I, Mathiesen BV, Hvelplund F, et al. Energy storage and smart energy systems. Int J Sustain Energy Plan Manag 2016. https://doi.org/10.5278/ijsepm.2016.11.2.

49. National Grid. Future Energy Scenarios. 2019.

50. Christensen OB, Goodess CM, Harris I, Watkiss P. European and Global Climate Change Projections. n.d.

51. Danish Energy Agency. Danish Technology Catalogue 2018.

52. Chiu LF, Lowe R. Ecology of heat pump performance: A socio-technical analysis. Smart Innov. Syst. Technol., vol. 163, Springer; 2020, p. 711-21. https://doi.org/10.1007/978-981-32-9868-2_60.

\section{Declarations}

\section{Acknowledgments}

The authors gratefully acknowledge support from UK Research and Innovation (UKRI) through the Heat Decarbonisation Theme of the Centre for Research into Energy Demand Solutions, CREDS, grant reference number EP/R 035288/1. We would like to thank R. Lowe for his comments and fruitful discussions.

\section{Author Contributions}


Tiziano Gallo Cassarino: Conceptualization, Methodology, Software, Validation, Formal analysis, Investigation, Writing Original Draft, Writing - Review \& Editing, Visualization.

Mark Barrett: Conceptualization, Methodology, Validation, Formal analysis, Investigation, Writing - Original Draft, Writing Review \& Editing , Visualization, Supervision, Project administration, Funding acquisition.

\section{Competing Interests statement}

The authors declare no competing interests.

\section{Figures}

a
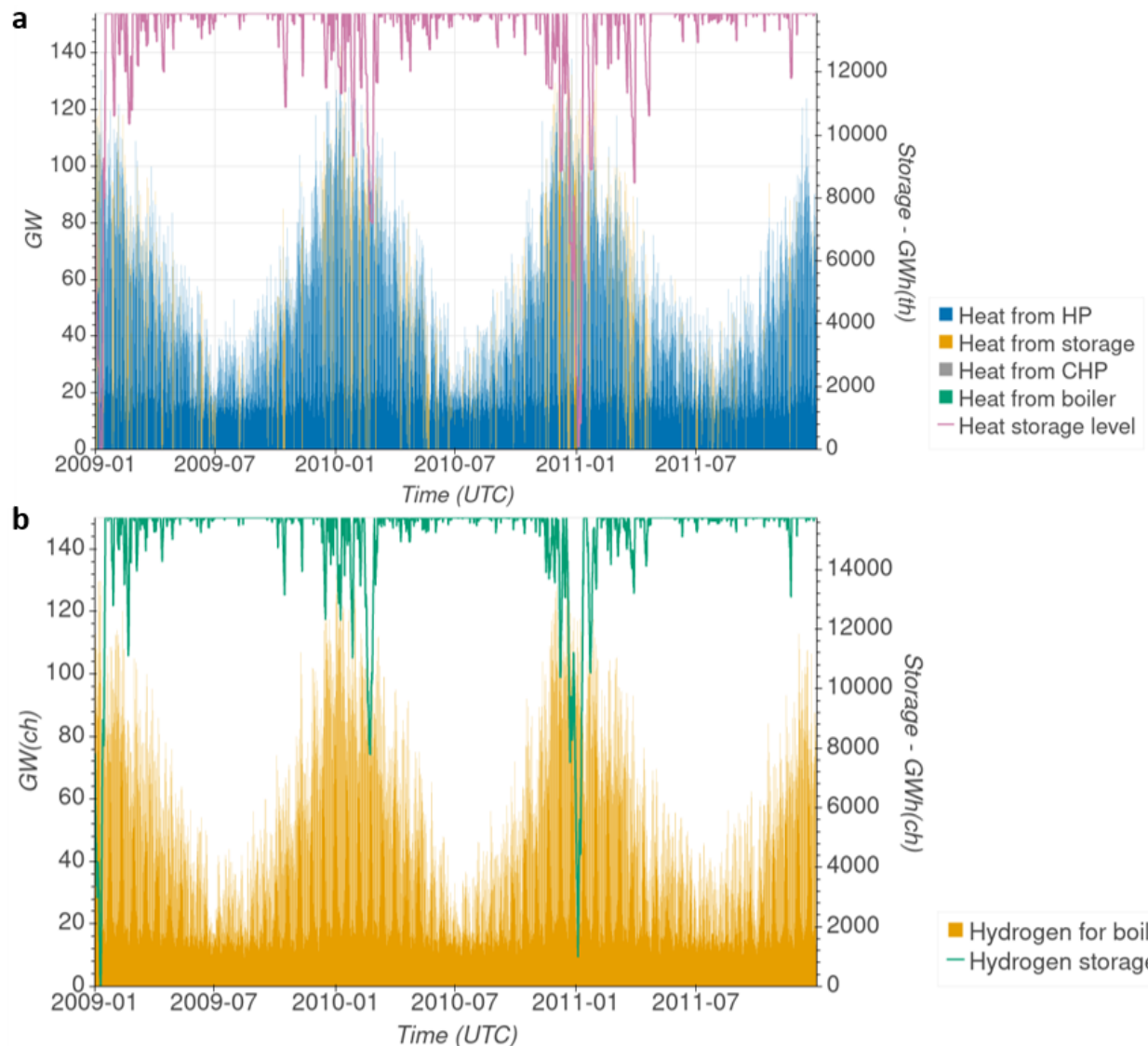

- Hydrogen for boilers

- Hydrogen storage level

c

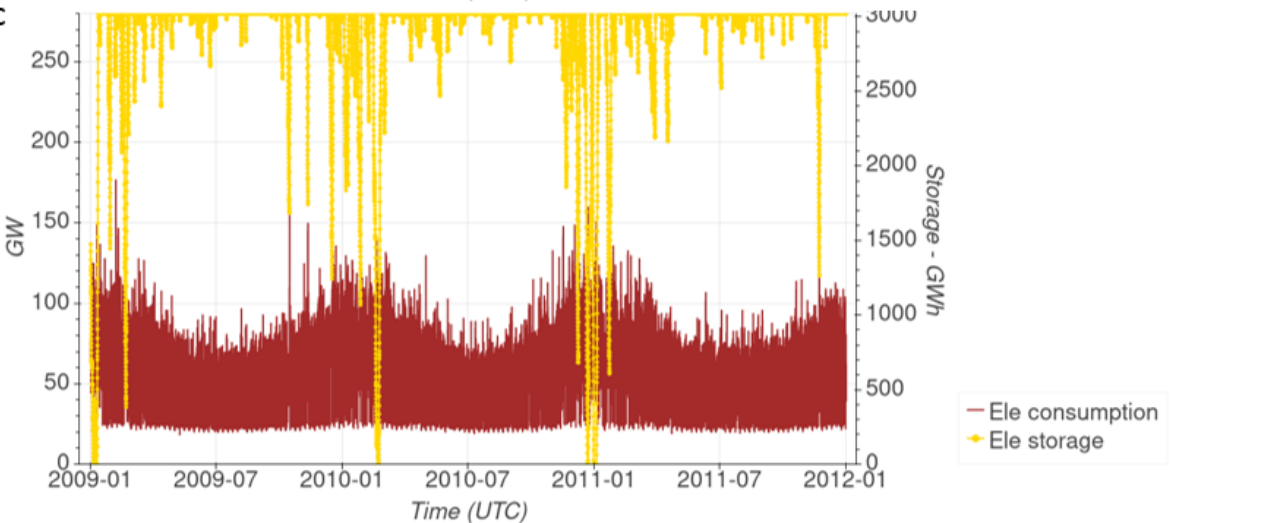

Figure 1 
Hourly dynamics between 2009-2011 of district heating, hydrogen, and electricity systems in the core scenarios. a, Hourly heat storage level (right axis) and delivered heat from heat pumps, heat storage, CHPs, boilers (left axis). b, Hourly hydrogen storage level (right axis) and delivered hydrogen for ammonia production and for boilers (left axis). c, Hourly electricity storage level (right axis) and system electricity consumption (left axis).

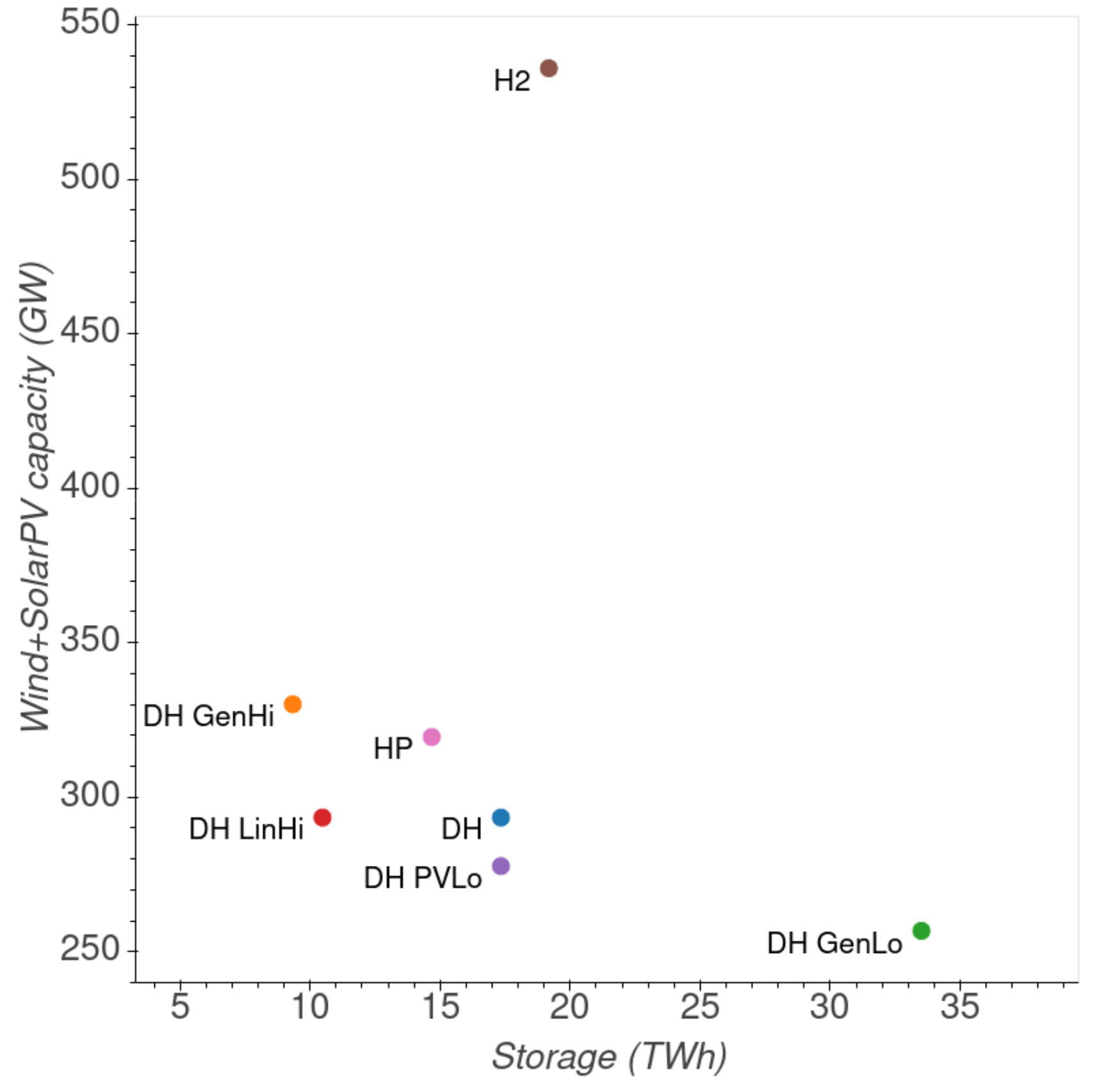

Figure 2

Storage size against renewable generation. Trade-off between total system storage size and renewable capacity (wind and solar PV) set for each scenario. The values for $\mathrm{DH}$ CChHi, DH CChLo, DH InsHi, DH InsLo are not shown, as they are are the same as the values of the $\mathrm{DH}$ core scenario. 


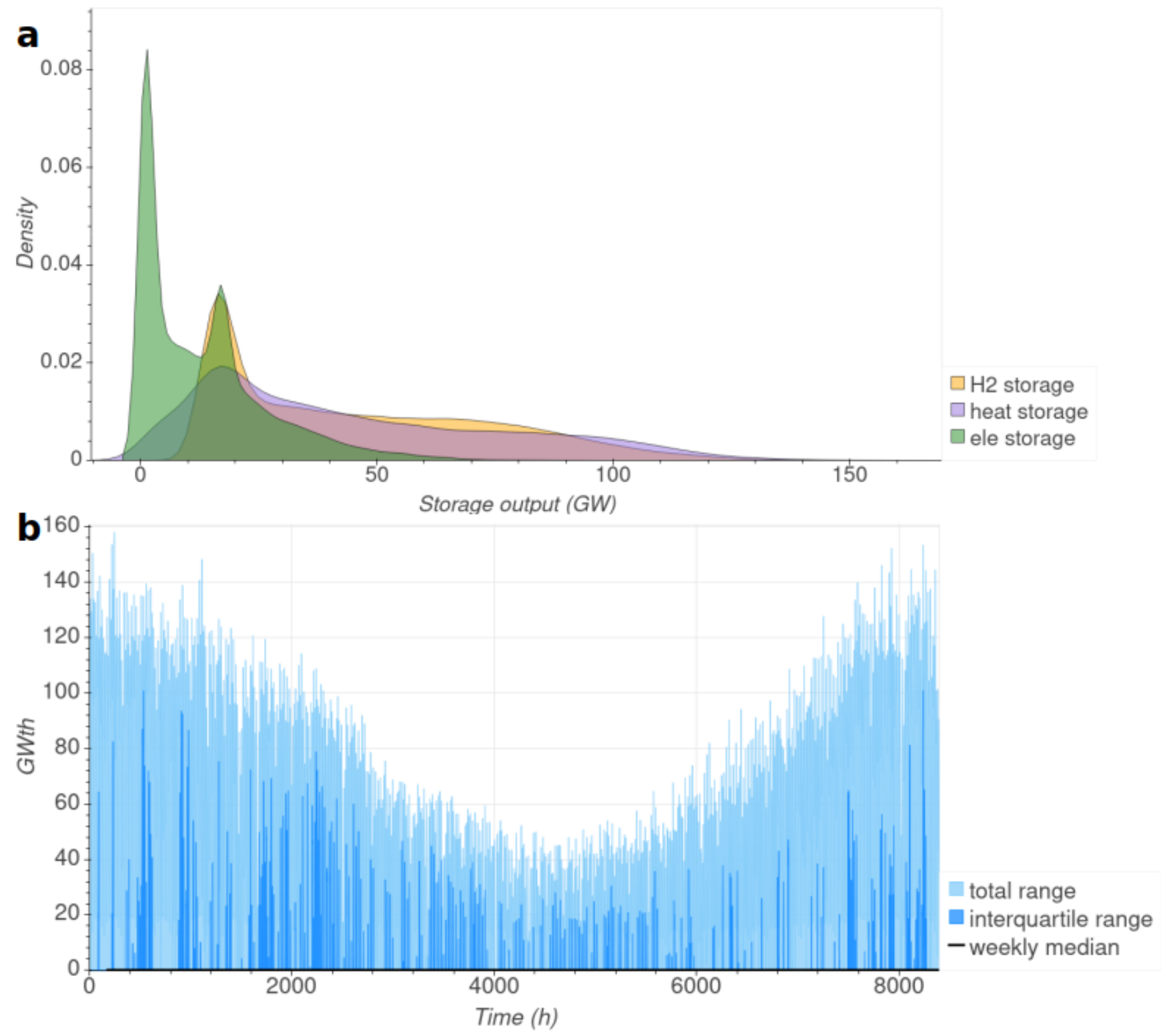

Figure 3

Hourly simulation of the storage output over 35 years (1980-2015). a, Frequency distribution of the hourly output from the hydrogen storage ( $\mathrm{H} 2$ core scenario), the heat storage (DH core scenario), and the electricity storage (HP core scenario). b, Annual distribution of the hourly heat storage output in the $\mathrm{DH}$ scenario. 


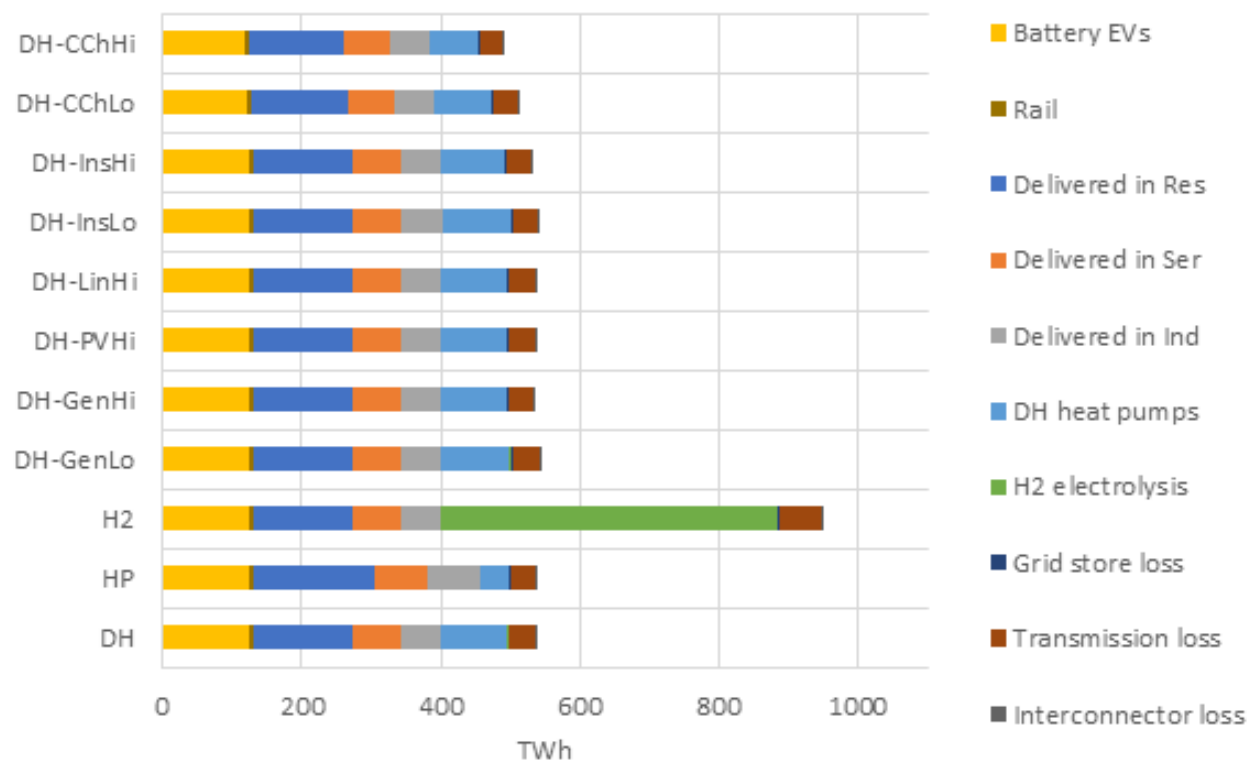

\section{Figure 4}

Electricity consumption in 2010 for each scenario. Annual electricity consumption in each scenario, subdivided by sector and technologies. EVs: electric vehicles; Res: residential; Ser: services; Ind: industry.

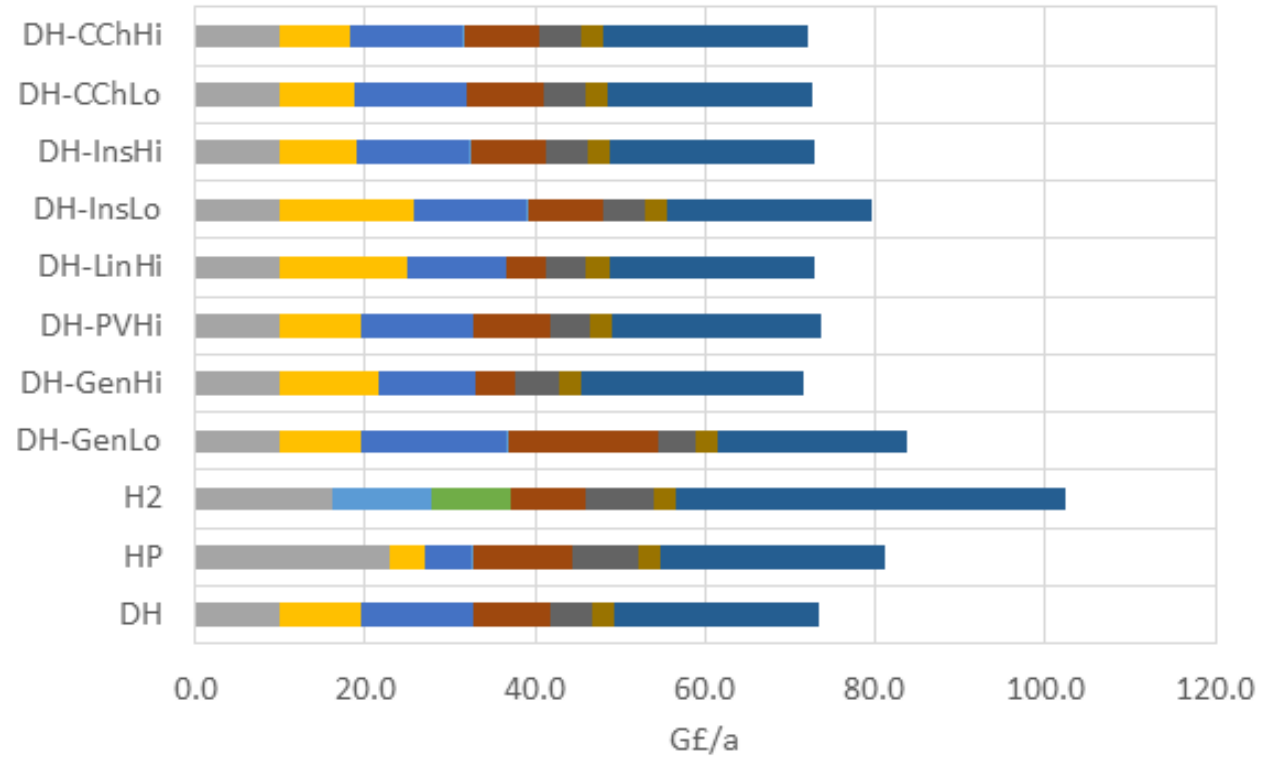

Consumer conversion

- $\mathrm{H} 2$ electrolyser

Elec network
DH conversion

- H2 store \& network

nuclear
DH store \& network

- Elec storage

Renewables

\section{Figure 5}

Annuitised system costs in 2010 for each scenario. Annuitized system costs divided by technology group. Consumer conversion: consumer heat pumps and hydrogen boilers; Renewables: wind farms, solar photovoltaic, hydroelectric. 


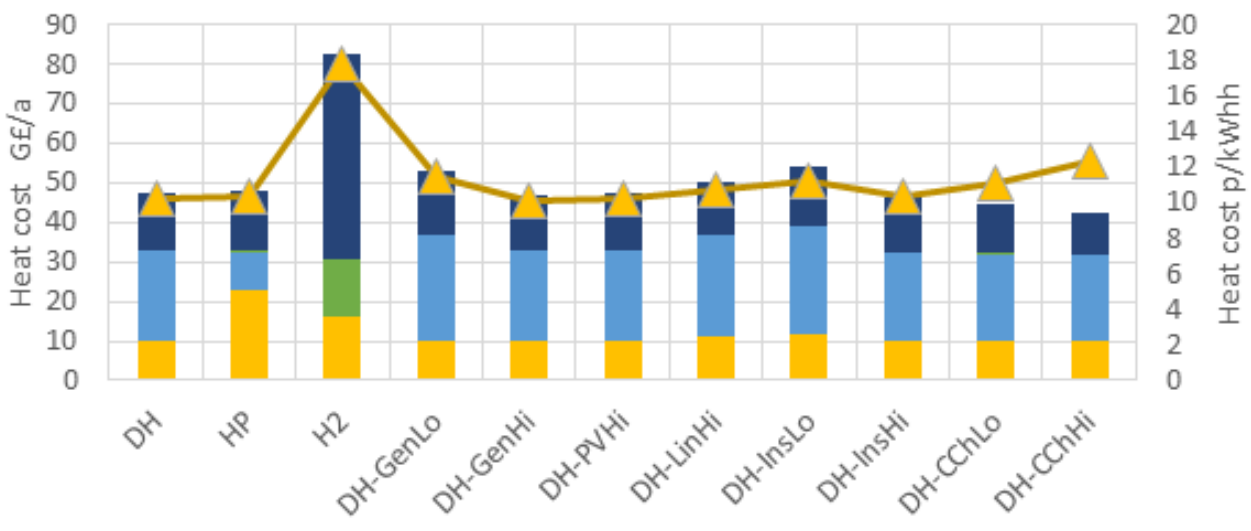

\section{Figure 6}

Annual heating costs in 2010. Total costs related to heat supply (left axis) include consumer heat pumps and boilers (Consumer), district heating (District heat), and most of the hydrogen component costs, i.e. boilers and electrolysers (Hydrogen), as well as the share of energy supply used to meet heat demand (Primary for heat). The yellow line shows the average consumer price for heating (right axis).

\section{Supplementary Files}

This is a list of supplementary files associated with this preprint. Click to download.

- GalloCassarinoBarrettsupplementaryinformation.docx 